\title{
EFEK SENTRA PEMOTONGAN AYAM TERHADAP KESEHATAN LINGKUNGAN MASYARAKAT PEMUKIMAN
}

\author{
Eka Apriyanti ${ }^{1}$ \\ ${ }^{1}$ Universitas Pembangunan Indonesia, Makassar \\ email: eka.apriyanti@rocketmail.com
}

\begin{abstract}
Abstrak
Penelitian ini bertujuan untuk mengkaji praktik sanitasi rumah potong ayam. Hal ini muncul berdasarkan pengakuan bahwa tempat pemotongan ayam yang berada di tengah pemukiman warga terkesan kurang memperhatikan pembuangan limbahnya, sehingga memunculkan kekhawatiran warga terhadap kesehatan lingkungan masyarakat pemukiman. Survei untuk penelitian ini menggunakan kuesioner dan observasi lapangan. Sebanyak 31 unit usaha pemotongan ayam teridentifikasi di daerah penelitian dimana 80\% dipilih secara acak. Temuan menunjukkan bahwa pengelolaan limbah padat pada sentra usaha pemotongan ayam tergolong cukup baik yaitu: telah menyediakan wadah penampungan limbah, letak wadah di luar bangunan, berupaya mengurangi bau kotoran ayam, tersedia TPS (kontainer) dan pengangkutan limbah oleh petugas kebersihan, namun untuk pengelolaan limbah cair tergolong sangat buruk yaitu: belum tersedia sarana pengolahan air limbah, tidak ada saluran khusus untuk limbah cair dan sebagian besar belum melakukan penyaringan air limbah sebelum dialirkan ke saluran pembuangan sehingga menimbulkan bau busuk. Hasil uji lab BOD dan COD limbah cair dari tempat pemotongan juga telah melampaui baku mutu lingkungan yakni sebesar 3204,7 mg/L dan nilai COD sebesar 5969,6 mg/L. Efek dari kegiatan pemotongan ayam terhadap kesehatan mayarakat pemukiman berdasarkan data yang diperoleh dari Puskesmas terdekat diketahui ada beberapa jenis penyakit yang diderita warga diakibatkan oleh kebersihan lingkungan yang tidak memadai, seperti penyakit saluran pernafasan atas, diare, cacingan, penyakit kulit dan penyakit lainnya. Namun demikian untuk memastikan hal tersebut diperlukan kajian/penelitian yang lebih mendalam. Studi ini merekomendasikan kepada pemerintah Kota untuk melakukan pemantauan secara periodik terhadap operasi pemotongan hewan, termasuk sentra pemotongan ayam, penegakan hukum dan peraturan sanitasi lingkungan di rumah pemotongan serta pendidikan lingkungan untuk para pengelola rumah pemotongan hewan dan penduduk.
\end{abstract}

Kata kunci: sanitasi, rumah potong ayam, limbah daging, praktik, polusi.

\begin{abstract}
This study aims to examine the practice of sanitation of chicken slaughter house. This arises based on the recognition that the chicken slaughtering place in the middle of the settlement seems less attention to the waste disposal citizens' concerns about the environmental health of residential communities. Surveys for this study used questionnaires and field observations. A total of 31 chicken-cutting businesses were identified in the study area where $80 \%$ were selected at random. The findings indicate that solid waste management at the chicken slaughtering center is good enough: it has provided waste collection container, the location of container outside the building, attempts to reduce the smell of chicken manure, available the TPS (container) and the transport of waste by the janitor, but for the waste management liquid is classified as very bad, namely: there is no wastewater treatment facilities, no special channels for liquid waste and most have not filtered the waste water before it is flooded into the sewer causing a foul odor. Laboratory test results of BOD and COD of liquid waste from slaughterhouses have also exceeded the environmental quality standard of $3204.7 \mathrm{mg} / \mathrm{L}$ and COD value of $5969.6 \mathrm{mg} / \mathrm{L}$. The effects of chicken slaughtering activities on the health of residential communities based on data obtained from the nearest Puskesmas are known to be some types of diseases suffered by residents caused by inadequate environmental hygiene, such as upper respiratory tract diseases, diarrhea, worms, skin diseases and other diseases. However, to ensure that more in-depth research / research is needed. The study recommends the city government to periodically monitor animal slaughter operations, including chicken cutting centers, law enforcement and environmental sanitation regulations in slaughter houses and environmental education for slaughterhouse and resident management.
\end{abstract}

Kata kunci: sanitation, chicken slaughter house, waste meat, polution. 
PENDAHULUAN

Usaha pemotongan hewan merupakan sarana yang tampaknya sudah menjadi kebutuhan manusia terutama masyarakat kota besar, dengan konsumsi daging khususnya daging ayam sudah cukup tinggi. Di lain pihak, dalam proses kegiatannya terdapat produk sampingan yaitu berupa limbah, baik limbah padat maupun limbah cair yang dapat mencemari lingkungan apabila dibuang langsung ke lingkungan tanpa pengolahan terlebih dahulu karena limbah tersebut mengandung bakteri patogen maupun yang non patogen.

Limbah-limbah tersebut berasal dari: ruangan peristirahatan ayam yang menghasilkan limbah padat dari kotoran ayam, proses penyembelihan ayam menghasilkan darah beku dan limbah cair yaitu air untuk menyiram atau membersihkan daerah pemotongan dan peralatannya yang bercampur dengan sisasisa darah. Bulu merupakan limbah padat yang berasal dari tempat (mesin) pencabutan bulu.

Limbah yang dihasilkan dari kegiatan rumah potong ayam menimbulkan masalah yang signifikan terhadap lingkungan. Terutama usaha pemotongan yang berada di tengah-tengah pemukiman warga dapat menimbulkan berbagai dampak, baik dampak sosial maupun dampak terhadap kesehatan masyarakat di sekitarnya, diantaranya muncul kekhawatiran warga terhadap wabah flu burung, meningkatnya polusi air dan udara, yang pada akhirnya akan menurunkan kualitas sanitasi lingkungan.

Kualitas pengelolaan rumah pemotongan, khususnya kepatuhan terhadap sanitasi lingkungan adalah kunci untuk kesehatan masyarakat. Praktik sanitasi lingkungan yang efisien di rumah pemotongan hewan dan program kebersihan daging merupakan prasyarat untuk hidup sehat masyarakat. Manfaatnya adalah kesehatan manusia, pengendalian penyakit hewan, pengolahan dan nilai bersih ritel, pembusukan dan penipuan yang berkurang dan membaiknya kebersihan lingkungan.

Sanitasi lingkungan di rumah pemotongan merupakan isu yang menonjol hampir di setiap negara berkembang dan telah dibahas oleh berbagai penulis di berbagai waktu dan wilayah. Studi yang telah dilakukan diantaranya penanganan dan pembuangan limbah oleh rumah jagal ke lingkungan merupakan penentu dari kondisi sanitasi lingkungan (Feron, J., Mensah, S. B. and Boateng, 2014 ) dan (Chika, G. E, 2015) namun dalam studi ini belum dibahas aspek pengelolaan limbah padat lainnya seperti sumber air dan kualitas air yang digunakan dan cara 
mengurangi polusi bau yang berasal dari kegiatan pengkandangan.

Studi lainnya tentang Manajemen Limbah Rumah Pemotongan Hewan telah dilakukan oleh (Adeyemo, Ayodeji \& Aiki-Raji, 2002) dan (Kosamu1, I. B. M., Mawenda, and Mapoma1, 2011) yang mengungkapkan bahwa limbah rumah pemotongan hewan memiliki implikasi lingkungan yang serius. Limbah pemotongan daging dapat menyebabkan pencemaran terhadap badan air terdekat. Oleh karena itu perlu dilakukan pemeriksaan air secara berkala untuk mengantisipasi kemungkinan adanya kontaminasi.

Efek dari kegiatan rumah jagal terhadap kesehatan penduduk kota diungkapkan oleh Singh, V. P. and Neelam, S. ( 2011 ) bahwa warga yang tinggal di sekitar rumah potong hewan mengalami penurunan kualitas kesehatan akibat dari pencemaran kualitas air dan udara. Kasus peningkatan batuk berlebih, demam tifoid, diare, malaria dan nyeri otot dilaporkan terjadi. Demikian pula diare, trypnosomiasis, infestasi parasit internal dan eksternal, demam dan kasus penurunan hasil susu juga dilaporkan pada hewan.

Berdasarkan hal tersebut di atas, perlu untuk menyelidiki secara empiris praktik sanitasi lingkungan melibatkan operator tempat usaha pemotongan. Ini akan menjadi alat untuk mengaudit keamanan lingkungan dan daging ayam. Dengan demikian dampak negatif (pencemaran lingkungan) dari tempat pemotongan hewan tidak akan bertentangan dengan dampak positif mereka (produksi daging) dan juga kenyamanan warga dan lingkungan disekitarnya.

\section{METODOLOGI}

Wilayah penelitian berada dalam wilayah administrasi Kota Makassar. Penelitian ini mengidentifikasi 31 unit usaha pemotongan ayam yang menyatu dengan pemukiman warga, dimana $80 \%$ dipilih secara acak (25 unit usaha). Teknik acak sederhana digunakan untuk memilih informan dari operator di masing-masing rumah pemotongan ayam yang dipilih. Dengan demikian, diperoleh 25 operator sampel dimana kuesioner diberikan.

Informasi yang dikumpulkan dari masing-masing tempat pemotongan termasuk profil responden meliputi umur, jenis kelamin, tingkat pendidikan, dan informasi yang berkaitan dengan praktik sanitasi seperti jumlah rata-rata ayam yang dipotong per hari, lamanya usaha, tata letak bangunan, sumber air dan kualitas air, metode pengelolaan limbah padat dan limbah cair, mendata jenis penyakit yang 
sering diderita penduduk dan jumlah kunjungan puskesmas di sekitar tempat usaha pemotongan ayam.

Data yang dikumpulkan melalui survei berkaitan dengan praktik sanitasi lingkungan di sentra pemotongan ayam. Data yang dikumpulkan dianalisis dengan menggunakan Statistik deskriptif, diagram dan Microsoft Excel.
HASIL DAN PEMBAHASAN

Bagian ini membahas profil responden dan memeriksa praktik sanitasi lingkungan di daerah penelitian.

\section{Profil Responden}

Profil Responden Profil responden yang didiskusikan meliputi umur, jenis kelamin, dan tingkat pendidikan.

Tabel 1.

Profil Responden

\begin{tabular}{|c|c|c|c|c|}
\hline & Profil & & $\begin{array}{c}\text { Jumlah } \\
\text { Responden }\end{array}$ & Persentase \\
\hline \multirow{3}{*}{1.} & \multirow{3}{*}{ Umur } & $20-40$ & 19 & $76 \%$ \\
\hline & & $>40$ & 6 & $24 \%$ \\
\hline & & Total & 25 & $100 \%$ \\
\hline \multirow{3}{*}{2.} & \multirow{3}{*}{$\begin{array}{l}\text { Jenis } \\
\text { Kelamin }\end{array}$} & Laki-laki & 23 & $92 \%$ \\
\hline & & Perempuan & 2 & $8 \%$ \\
\hline & & Total & 25 & $100 \%$ \\
\hline \multirow{4}{*}{3.} & \multirow{4}{*}{$\begin{array}{l}\text { Tingkat } \\
\text { Pendidikan }\end{array}$} & Tamat SD & 4 & $16 \%$ \\
\hline & & Tamat SMP & 10 & $40 \%$ \\
\hline & & Tamat SMA & 11 & $44 \%$ \\
\hline & & Total & 25 & $100 \%$ \\
\hline
\end{tabular}

Temuan ini menunjukkan bahwa 92\% laki-laki terlibat dalam usaha pemotongan ayam dan $8 \%$ perempuan. Ditemukannya perempuan sebagai operator karena pemotongan ayam relatif lebih ringan pengerjaannya dibanding dengan pemotongan hewan besar. Usia responden dikelompokkan menjadi dua (antara 20 sampai 40 tahun) dan (40 tahun keatas). Ini bertujuan untuk menciptakan dikotomi antara operator dewasa muda dan dewasa tua. Temuan menunjukkan bahwa $76 \%$ operator berusia antara 20-40 sementara 24\% diatas 40 Tahun. Hal ini menunjukkan bahwa responden yang terlibat sebagai operator berada dalam usia 
dewasa muda. Temuan mengenai kualifikasi pendidikan untuk operator pemotongan ayam yakni bahwa $16 \%$ operator memiliki pendidikan dasar, $40 \%$ memiliki pendidikan menengah dan $44 \%$ memiliki pendidikan menengah atas.

\section{Atribut Sentra Pemotongan Ayam}

1. Jumlah ayam yang dipotong per hari
Kapasitas pemotongan ayam tiap unit usaha tidak sama, dengan kata lain ada usaha yang kapasitas usahanya besar dan ada yang kapasitasnya kecil. Untuk mengetahui besarnya kapasitas usaha pemotongan ayam diukur dari rata-rata banyaknya ayam yang dipotong/hari sebagaimana yang terlihat pada diagram berikut.

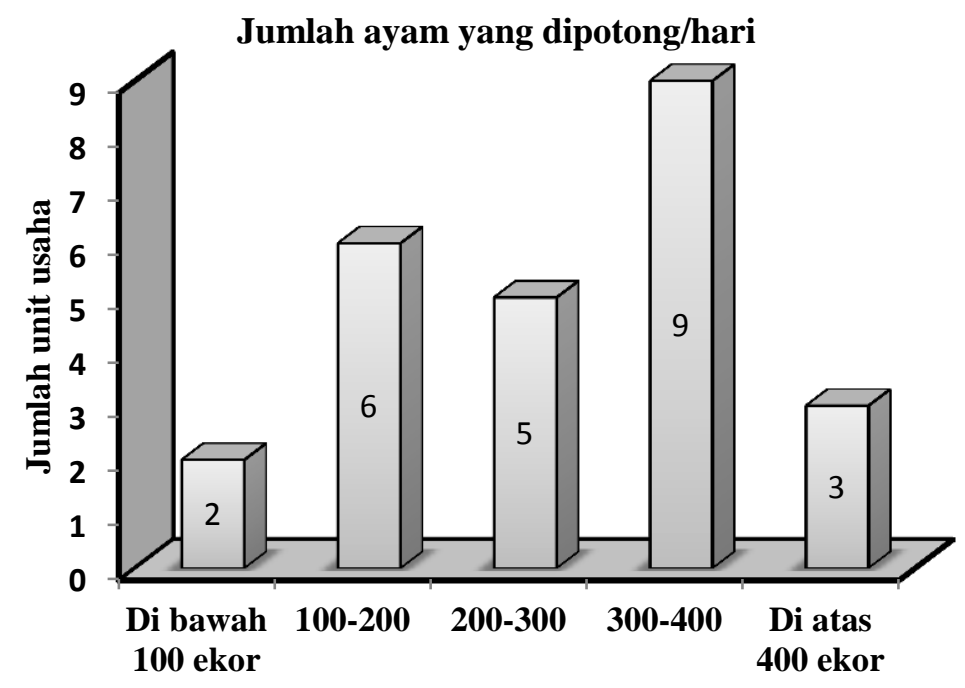

Gambar 1.

Jumlah Ayam yang dipotong per Hari

Diagram batang menunjukkan bahwa usaha pemotongan ayam yang paling banyak jumlahnya adalah yang jumlah pemotongannya berkisar antara 300-400 ekor/hari yakni sebanyak 9 unit usaha, kemudian yang jumlah pemotongannya antara 100-200 ekor yakni sebanyak 6 unit usaha, disusul antara 200300 ekor sebanyak 5 unit usaha dan diatas 400 ekor sebanyak 3 unit usaha, yang paling sedikit jumlahnya adalah yang jumlah pemotongannya dibawah 100 ekor/hari yakni sebanyak 2 unit.
2. Tata letak bangunan, sumber air dan kualitas air

Tata letak bangunan rumah penduduk dimana terdapat usaha pemotongan ayam di lokasi penelitian cukup teratur. Dari hasil observasi yang dilakukan terlihat keteraturan jajaran rumah penduduk dan rumah tempat usaha pemotongan ayam berada tertata cukup baik karena mempunyai jalan dan atau gang yang semuanya mempunyai saluran air. Adapun sifat bangunan usaha pemotongan beberapa masih semi 
permanen, sebagaimana dapat dilihat pada

Tabel 2.

Tabel 2.

Sifat bangunan usaha pemotongan ayam

\begin{tabular}{clcc}
\hline No. & Sifat bangunan & $\begin{array}{c}\text { Jumlah } \\
\text { unit usaha }\end{array}$ & Persentase \\
\hline 1. & Permanen & 17 & $68 \%$ \\
2. & Semi permanen & 8 & $32 \%$ \\
\hline & Total & 25 & $100 \%$ \\
\hline
\end{tabular}

Temuan ini menunjukkan bahwa sebanyak 17 unit usaha pemotongan ayam bangunannya bersifat permanen, sisanya sebanyak 8 unit usaha bangunannya masih bersifat semi permanen. Bangunan usaha yang sifatnya permanen merupakan bangunan yang menyatu dengan tempat tinggal pemiliknya dan sudah dibangun sedemikian rupa untuk keperluan kegiatan usaha pemotongan ayam sedangkan bangunan usaha yang bangunannya bersifat semi permanen adalah bangunan yang dikontrak oleh pengelola usaha khusus untuk kegiatan usaha pemotongan tidak digunakan sebagai tempat tinggal.

Sumber air yang digunakan oleh para pengelola usaha pemotongan ayam adalah air sumur (sumur bor).

Tabel 3.

Kualitas Air berdasarkan Parameter Fisik

\begin{tabular}{clc}
\hline No. & Parameter Fisik & Kualitas air sumur \\
\hline 1. & Warna & Cukup Jernih \\
2. & Rasa & Tawar \\
3. & Bau & Tidak Berbau \\
\hline
\end{tabular}

Kualitas air sumur pengelola usaha pemotongan ayam menurut hasil pengamatan, hanya dilihat dari tiga segi, yakni dari segi warna, rasa, dan bau. Mengenai warna, umumnya air sumur hasil pengamatan cukup jernih, dengan kata lain tidak sejernih air PDAM karena masih ada sedikit warna lain pada air sumur tersebut, yakni agak kekuningkuningan (agak keruh), adapun rasa air sumur yang diamati cukup tawar, sedangkan bau air sumur tidak berbau, meskipun tidak sama persis dengan air PDAM namun untuk keperluan usaha 
pemotongan ayam, air yang digunakan sudah tergolong baik.

3. Lama usaha pemotongan ayam

Lama usaha pemotongan ayam merupakan salah satu konsekuensi dari kegiatan dalam lingkup rumah tangga. Oleh sebagian besar warga masyarakat dijadikan sebagai pekerjaan pokok. Lama usaha pemotongan ayam mempunyai kaitan erat dengan tingkat pengetahuan dan pengalaman seseorang. Seseorang yang baru mengusahakan pemotongan ayam biasanya belum banyak pengalaman dan pengetahuan dalam mengatasi hambatan-hambatan, sedangkan yang sudah lama menjalankan usaha pemotongan ayam dapat mengatasi sendiri. Dalam keadaan seperti inilah yang dapat mempengaruhi praktik sanitasi lingkungan. Distribusi menurut lama usaha pemotongan ayam, terlihat pada diagram berikut.

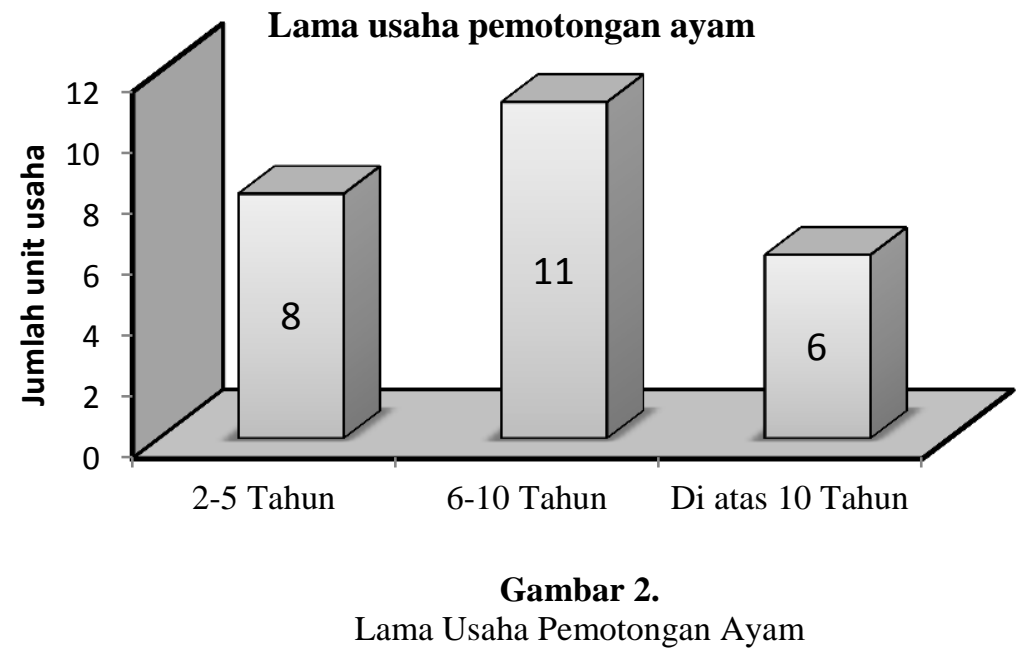

Gambar diatas menunjukkan proporsi tertinggi berada pada kelompok lama usaha pemotongan ayam antara 6-10 tahun yaitu 11 unit usaha, menyusul 8 unit usaha kelompok lama usaha 2-5 tahun dan 6 unit usaha berada pada kelompok lama usaha diatas 10 tahun. Banyaknya jumlah unit usaha yang berada pada kelompok umur 6-10 tahun disebabkan oleh karena usaha tersebut cukup menjanjikan keuntungan dan bahkan sebagian besar merupakan mata pencaharian pokok bagi warga yang menggeluti usaha tersebut.

\section{Praktek Sanitasi Lingkungan di Sentra Pemotongan Ayam}

Investigasi terhadap metode pengelolaan limbah tempat pemotongan ayam.

\section{Pengelolaan Limbah Padat:}

1. Konstruksi/bentuk Tempat penampungan sementara. 
Tabel 4.

Konstruksi/bentuk Tempat Penampungan Sementara

\begin{tabular}{llcc}
\hline No. & Konstruksi/bentuk TPS sampah industri & $\begin{array}{c}\text { Jumlah } \\
\text { unit usaha }\end{array}$ & Persentase \\
\hline 1 & Keranjang plastik/Tembus air & 22 & $88 \%$ \\
2 & Ember/Kedap air & 3 & $12 \%$ \\
\hline & Total & 25 & $100 \%$
\end{tabular}

Bentuk tempat sampah sementara umumnya menggunakan keranjang plastik yang tembus air yakni sebanyak 22 unit usaha dan selebihnya menggunakan ember plastik yang tertutup. Keranjang plastik

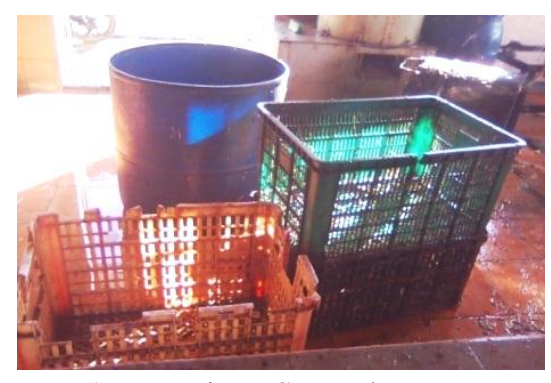

Foto 1. Keranjang Sampah digunakan untuk mengeringkan sampah karena sifat sampah yang basah, setelah kering baru kemudian sampah dimasukkan ke dalam karung plastik.

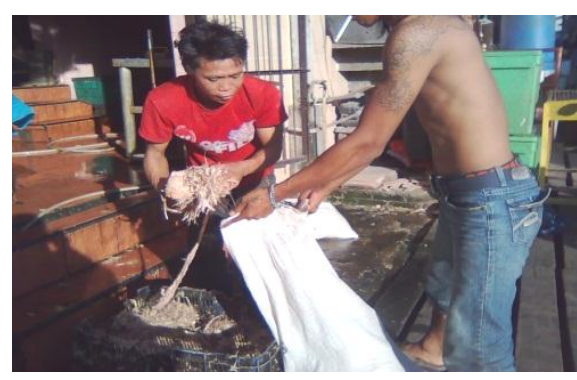

Foto 2. Memasukkan limbah (bulu dan jeroan) ke dalam karung
2. Mengurangi polusi bau

Sebagian besar tempat usaha telah kandang dengan sekam atau serbuk kayu agar baunya tidak menyebar. melakukan pengelolaan untuk mengurangi polusi bau yang ditimbulkan dari kotoran ayam, yakni dengan melapisi lantai

Tabel 4.

Cara Mengurangi Polusi Bau

\begin{tabular}{|c|l|c|c|}
\hline No. & \multicolumn{1}{|c|}{ Cara mengurangi polusi bau } & $\begin{array}{c}\text { Jumlah } \\
\text { Unit usaha }\end{array}$ & Persentase \\
\hline 1. & Melapisi lantai kandang dengan sekam & 8 & $32 \%$ \\
\hline 2. & Melapisi lantai kandang dengan serbuk kayu & 11 & $44 \%$ \\
\hline 3. & Tidak melapisi kandang & 6 & $24 \%$ \\
\hline & Total & 25 & $100 \%$ \\
\hline
\end{tabular}


3. Pengangkutan

Pengangkutan sampah atau limbah padat usaha pemotongan ayam diangkut oleh mobil/truk pengangkut sampah dari Dinas Kebersihan Kota. Limbah yang telah dikumpulkan oleh pengelola di depan

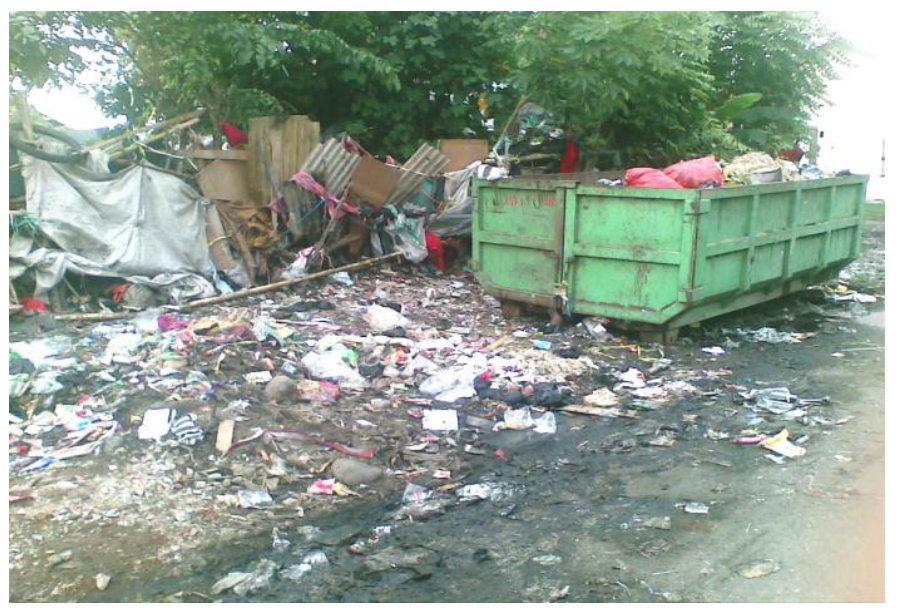

Foto 3. Kondisi TPS/container di lokasi penelitian

Hal-hal yang perlu diperhatikan dalam pengelolaan limbah padat yaitu tidak menaruh sampah di atas tanah terbuka, sebaiknya tersedia bak/tempat sampah. Syarat-syarat tempat sampah yang baik adalah mudah diisi, tidak tembus air, disimpan di bagian depan pekarangan atau di dalam pagar dan tidak mudah digulingkan oleh binatang. Sampah yang terkumpul pada bak sampah, kemudian diangkut dalam keadaan tertutup dari rumah-rumah ke tempat pengumpulan, tempat pemanfaatan kembali atau ke tempat pembuangan sampah. Tempat untuk membuang sampah harus memenuhi syarat, yaitu tidak dekat dengan sumber air minum, tempat tersebut tidak terkena bangunan tempat usaha mereka maupun yang dikumpulkan di TPS (kontainer) akan diangkut oleh petugas mobil pengangkut sampah yang beroperasi pada malam hari ke Tempat Pembuangan Akhir (TPA). 


\section{Pengelolaan Limbah Cair:}

1. Sarana pengolahan limbah cair

Agar air tidak mencemari lingkungan maka perlu dikelola dengan baik walaupun pada dasarnya lingkungan mempunyai daya dukung yang cukup besar terhadap gangguan yang timbul karena pencemaran air limbah tersebut, sebaiknya air limbah mendapat perhatian dari masyarakat agar tidak menurunkan kualitas lingkungan.

Dari hasil observasi yang dilakukan pada 25 usaha pemotongan ayam, sarana pengolahan limbah cair tidak tersedia atau tidak dilakukan penanganan terlebih dahulu seperti: penampungan, pengendapan kemudian dialirkan untuk dibuang. Limbah cair langsung dialirkan ke saluran permukiman/drainase tanpa ada pengolahan terlebih dahulu.

Tabel 5.

Data Bak Penampungan Limbah

\begin{tabular}{llll}
\hline No. & Bak penampungan limbah & $\begin{array}{l}\text { Jumlah } \\
\text { unit usaha }\end{array}$ & Persentase \\
\hline 1. & Tersedia & 0 & 0 \\
2. & Tidak Tersedia & 25 & $100 \%$ \\
\hline & Total & 25 & $100 \%$ \\
\hline
\end{tabular}

2. Saluran air limbah

Agar tidak mencemari lingkungan, limbah cair usaha pemotongan sebaiknya dialirkan melalui saluran khusus yang terpisah dengan saluran limbah rumah tangga. Salah satu cara yang dapat dilakukan adalah dengan mengalirkan limbah melalui pipa paralon atau saluran yang tertutup dan terpisah dari saluran permukiman sehingga saluran air permukiman tidak menimbulkan bau busuk.

Tabel 6.

Saluran Air Limbah

\begin{tabular}{llll}
\hline No. & Saluran Air Limbah & $\begin{array}{l}\text { Jumlah } \\
\text { unit usaha }\end{array}$ & Persentase \\
\hline 1. & Tertutup dan terpisah & 0 & 0 \\
2. & Terbuka dan menyatu dengan limbah domestik & 25 & $100 \%$ \\
\hline & Total & 25 & $100 \%$ \\
\hline
\end{tabular}

Dari hasil observasi yang limbah, limbah cair hasil pemotongan dilakukan di sentra usaha pemotongan langsung dialirkan ke got/selokan menyatu tidak tersedia saluran khusus untuk air 
dengan limbah domestik/limbah cair rumah tangga.

\section{Penggunaan alat penyaring}

Salah satu cara pengelolaan limbah cair yang dilakukan oleh pengelola adalah dengan menempatkan saringan pada saluran air yang terdapat di dalam rumah dimana kegiatan usaha berlangsung. Saringan tersebut terbuat dari keranjang plastik dan dipasang pada ujung/mulut saluran air dengan maksud menyaring kotoran berupa bulu-bulu kecil, lemak dan ampas dari proses pembersihan jeroan ayam agar tidak ikut bersama air limbah mengalir ke saluran air permukiman/drainase. Berikut adalah distribusi usaha pemotongan ayam memasang saringan pada saluran airnya.

Tabel 7.

Pemasangan Saringan

\begin{tabular}{llll}
\hline No. & Memasang saringan & $\begin{array}{l}\text { Jumlah } \\
\text { unit usaha }\end{array}$ & Persentase \\
\hline 1. & Ya & 5 & $20 \%$ \\
2. & Tidak & 20 & $80 \%$ \\
\hline & Total & 25 & $100 \%$
\end{tabular}

Temuan ini menunjukkan bahwa umumnya sebanyak $80 \%$ usaha pemotongan ayam belum memasang saringan pada saluran air mereka. Mereka beranggapan bahwa sudah tidak ada lagi kotoran atau sampah lain yang akan ikut bersama air limbah yang mereka buang, sebab mereka sudah mengumpulkan dan menampungnya pada wadah yang mereka sudah siapkan, baik yang berupa keranjang platik, ember maupun karung plastik.

\section{Tujuan pengaliran air limbah}

Pengelola usaha pemotongan ayam mengalirkan limbah cair ke saluran permukiman/drainase yang berada di depan atau di samping bangunan usaha mereka yang lebarnya $30-50 \mathrm{~cm}$. Saluran air tersebut juga digunakan oleh warga masyarakat umumnya sebagai saluran tempat membuang air limbah domestik. Dari saluran permukiman, air limbah mengarah ke kanal yang berada di daerah Kelapa Tiga (lihat Foto 4 dan 5) yang berjarak \pm 100 meter dari sentra pemotongan ayam. Berdasarkan hasil observasi dan keterangan dari warga di sekitar kanal, air yang ada di kanal tersebut mengarah ke Sungai Pampang. 


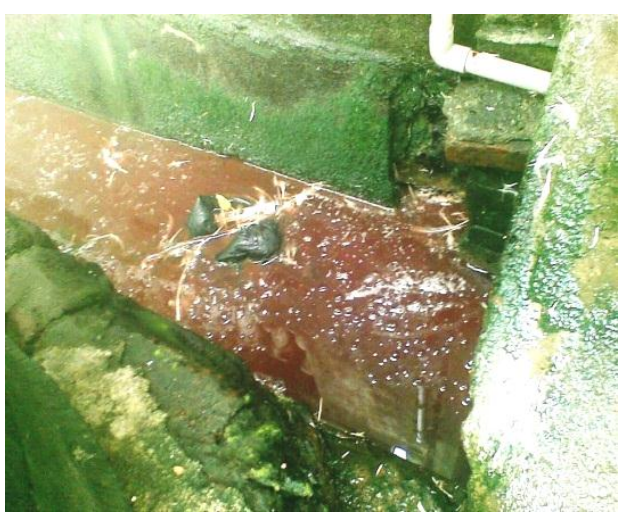

Foto 4. Selokan/saluran air limbah

5. Kandungan BOD dan COD limbah cair usaha pemotongan ayam

Limbah cair usaha pemotongan hewan berasal dari kegiatan pengkandangan dan pemotongan. Dari pengkandangan ternak, limbah cair dihasilkan dari kegiatan pencucian/sanitasi kandang dan limbah cair yang terkontaminasi limbah padat (sisa pakan dan kotoran ternak).

Dari kegiatan pemotongan ternak, limbah cair yang dihasilkan meliputi:

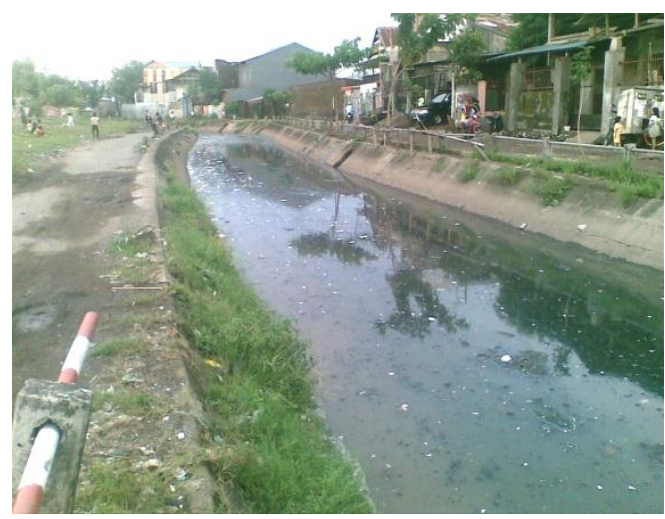

Foto 5. Kanal tempat tujuan pengaliran air limbah

(a) darah dari penyembelihan, (b) air limbah pencucian ruang pemotongan, (c) air limbah pencucian jeroan. Berdasarkan karakteristiknya, limbah cair dari kegiatan usaha pemotongan adalah mengandung bahan organik, padatan tersuspensi, lemak, nitrogen dan fosfor. Berikut ini ditampilkan kandungan BOD dan COD usaha pemotongan ayam di Makassar.

Tabel 8.

Parameter BOD dan COD

\begin{tabular}{llllll}
\hline No. & Parameter & Satuan & Hasil & Baku Mutu & Metode Uji/Teknik \\
\hline 1 & BOD & mg/L & 3204,7000 & 150 & SNI 19-2875-1992 \\
2 & COD & mg/L & 5969,6000 & 400 & SNI 06-6989,15-2004 \\
\hline
\end{tabular}

Sumber: Laboratoriun Uji dan Kalibrasi BBIHP Makassar.

Berdasarkan Peraturan Menteri Negara Lingkungan Hidup Nomor 02 Tahun 2006 tentang baku mutu air limbah bagi kegiatan pemotongan hewan, kadar maksimum untuk nilai BOD adalah sebesar $150 \mathrm{mg} / \mathrm{L}$, sedangkan nilai COD sebesar $400 \mathrm{mg} / \mathrm{L}$. 
Hasil uji laboratorium BOD dan COD air limbah hasil pemotongan ayam diperoleh nilai BOD yakni sebesar 3204,7 $\mathrm{mg} / \mathrm{L}$ dan nilai COD sebesar 5969,6 mg/L. Jika dikaitkan dengan batas maksimum yang ditetapkan dalam Peraturan Pemerintah, maka dapat dinyatakan bahwa air limbah hasil kegiatan usaha pemotongan ayam ini telah jauh melampaui baku mutu lingkungan sehingga sangat berpotensi menimbulkan pencemaran jika dibuang atau dilepas begitu saja ke lingkungan.

Hal ini mengindikasikan bahwa pihak pengelola perlu melakukan pengolahan air limbah sebelum air limbah dibuang ke lingkungan, sehingga mutu air limbah yang dibuang tidak melampaui baku mutu air sebagaimana yang telah ditetapkan oleh pemerintah. Air limbah yang tidak dikelola dengan baik akan dapat menimbulkan gangguan, terutama gangguan kesehatan.
DOI : doi.org/10.21009/jgg.071.03

Kebersihan Lingkungan dan Kesehatan Masyarakat Pemukiman

Dari hasil pengamatan di lokasi penelitian terlihat bahwa kebersihan lingkungan belum maksimal. Hal ini disebabkan masih terlihat sampah (bulu dan jeroan) yang diletakkan di depan atau disamping bangunan tempat pemotongan ayam. Sampah tersebut ditempatkan dalam keranjang-keranjang plastik yang terbuka sehingga menimbulkan bau amis yang bisa mengundang serangga seperti lalat dan semut, sedangkan air limbah hasil pemotongan ayam langsung dialirkan ke got/selokan di depan rumah, mengakibatkan kualitas udara di sekitar lokasi penelitian menjadi buruk. Hal tersebut dapat dirasakan dengan adanya bau yang cukup menyengat. Kondisi seperti ini tentu saja sangat tidak baik untuk kesehatan masyarakat, karena dapat menimbulkan berbagai jenis penyakit, sebagaimana ditampilkan pada Tabel dibawah ini.

Tabel 9.

Jumlah Kunjungan di Puskesmas yang berada disekitar Lokasi Penelitian

No. Jenis Penyakit

$1 \quad$ Saluran pernafasan atas

2 Lambung

3 Ginguitis dan periontal
Jumlah Kunjungan

Puskesmas Bara-barayya 


\begin{tabular}{lll}
\hline 4 & Sistem otot dan jaringan lain & 1371 \\
5 & Diare & 1276 \\
6 & Kulit karena infeksi & 693 \\
7 & Pulpa dan jaringan periodental & 978 \\
8 & Vulnus (luka) & 1657 \\
9 & Hypertensi & 506 \\
10 & Telinga & 0 \\
11 & Lainnya & 1581 \\
\hline & Total & 20973
\end{tabular}

Sumber: Puskesmas Bara-barayya, Kota Makassar 2015.

Diantara berbagai jenis penyakit sebagaimana Tabel diatas, ada beberapa jenis penyakit yang dapat diakibatkan baik secara langsung maupun tidak langsung oleh faktor lingkungan, seperti penyakit saluran pernafasan atas, diare, cacingan, penyakit kulit dan penyakit lainnya.

Boleh jadi tingginya intensitas kunjungan ke puskesmas berdasarkan jenis penyakit yang diderita warga tersebut diakibatkan oleh kebersihan lingkungan yang tidak memadai. Namun demikian untuk memastikan hal tersebut diperlukan kajian/penelitian yang lebih mendalam.

\section{KESIMPULAN}

Pentingnya hasil analisis efek sentra pemotongan ayam dalam upaya pengendalian limbah terhadap kesehatan lingkungan masyarakat pemukiman, adalah dilakukan karena berpotensi menimbulkan pencemaran lingkungan yang bisa berdampak negatif terhadap kesehatan warga.

Praktik sanitasi lingkungan SPA, dari aspek pengelolaan limbah padat tergolong cukup baik yaitu: telah menyediakan wadah penampungan limbah, letak wadah di luar bangunan, berupaya mengurangi bau kotoran ayam, tersedia TPS (kontainer) dan pengangkutan limbah oleh petugas kebersihan, namun dari aspek pengelolaan limbah cair tergolong sangat buruk yaitu: belum tersedia sarana pengolahan air limbah, tidak ada saluran khusus untuk limbah cair dan sebagian besar belum melakukan penyaringan air limbah sebelum dialirkan ke saluran pembuangan sehingga menimbulkan bau busuk. Hal ini diperkuat dengan hasil uji laboratorium BOD dan COD limbah cair yang nilainya jauh melampaui baku mutu lingkungan 
yakni sebesar 3204,7 mg/L dan nilai COD sebesar 5969,6 mg/L.

Berdasarkan hal tersebut di atas, dapat direkomendasikan bahwa kegiatan pemotongan harus dipantau secara periodik, adanya penegakan hukum dan peraturan sanitasi lingkungan di rumah pemotongan. Selain itu pembinaan/penyuluhan/pendidikan lingkungan juga dibutuhkan bagi operator dan warga. Ini akan memungkinkan mereka untuk mementingkan dimensi lingkungan yang melekat pada kegiatan penanganan daging. Pembinaan juga perlu diarahkan untuk menemukan cara bagaimana pemanfaatan limbah atau menggunakan kembali bagian hewan yang tidak dapat dikonsumsi. Ini akan membantu mengurangi limbah dan meningkatkan kesempatan kerja

\section{DAFTAR PUSTAKA}

Adeyemo, O., Adeyemi, I. and Awosanya, E. (2009). Cattle Cruelty and Risks of Meat contamination at Akinyele Cattle Market and Slaughter Slab in Oyo State, Nigeria. Tropical Animal Health and Production, 41, 1715- 1721.

Afon, and Fadare, (2011): Waste handling practices at abattoirs: experience from Ile Ife, Nigeria. Ife Planning Journal Vol. 4 No 1 pp.111- 121.
Badan Standardisasi Nasional. 1999. Rumah Pemotongan Unggas. Jakarta: Ditjen Peternakan.

Chika, G. E. (2015). Environmental Sanitation Situation in Abattoirs in Onitsha Metropolis. Knowledge Review Volume 32 No. 1

Chukwu, O. Adeoye, P. A. and Chidiebere, I. (2011). Abattoir wastes generation, Management and the Environment: A Case of Minna, North Central Nigeria. International Journal of Biosciences Vol 1, No. 6, pp.101-109.

Daramola, O. P. (2012). Clapping With One Hand: The Case of Urban Environmental Sanitation Practices in Nigeria Journal of Applied Technology in Environmental Sanitation, Vol. 2 No.4, pp. 223-228.

Daramola, O. P. (2015). Environmental Sanitation Practices in Residential Areas of Ibadan Metropolis. A Thesis Submitted in Partial Fulfillment of the Requirement for the Award of Doctor of Philosophy Degree in the Department of Urban And Regional Planning, Faculty of Environmental Design and Management, Obafemi Awolowo University, Ile-Ife, Nigeria.

Feron, J., Mensah, S. B. and Boateng, V. (2014). Abattoir Operations, Waste Generation and Management in the Tamale Metropolis: Case Study of the Tamale Slaughterhouse. Journal of Public Health and 
Epidemiology Vol 6, No. 1, pp1419.

Kandun, I. 2014. Sanitasi Lingkungan Dalam Memelihara Kesehatan Lingkungan. Online (http://www.depkes..go.id/info /.html).

Kecamatan Makassar dalam Angka 2015. Makassar: BPS Kota Makassar.

Keman. 2014. Pengaruh Lingkungan Terhadap Kesehatan, Jurnal Kesehatan Lingkungan. Online.

(http://adikristanto.net/?p=432)

Keputusan Menteri Pertanian No. 425/Kpts/01.2107/2001.

Tentang Pedoman Budidaya Ternak Ayam Petelur Yang Baik. Jakarta: Kantor Menteri Negara Pertanian Kristanto, P. 2002. Ekologi Industri. Yogyakarta: Andi.

Makmur. 1989. Pengelolaan Limbah Rumah Potong Hewan. Bogor: Dinas Peternakan.

Omole, D. O. and Ogbiye, A. S. (2013). An Evaluation of Slaughterhouse Wastes in South West Nigeria. American Journal of Environmental Protection Vol. 2, No. 3, pp. 85-89.
Priyatno. 1999. Mendirikan Usaha Pemotongan Ayam. Jakarta: Penebar Swadaya.

Singh, V. P. and Neelam, S. ( 2011). A Survey Report on Impact of Abattoir Activities and Management on Residential Neighbourhoods.. Indian Journal of Veterinarians, Vol. 6, No. 3, pp. 973 -978.

Soeparno. 1994. Ilmu dan Teknologi Daging. Yogyakarta: Gadjah Mada University Press.

Supartono, Y.,Yuliando. 2007. Analisis Kelayakan Finansial Usaha Pemotongan Ayam Tradisional DI Yogyakarta. Online. (http://ritahen.ifastnet.com).

Suriasumantri. 2003. Filsafat Ilmu Sebuah Pengantar Populer. Jakarta: Pustaka Sinar Harapan.

Surat Keputusan Menteri Pertanian Nomor 557/KPTS/TN.520/9/1987

Tentang Syarat-syarat Rumah Pemotongan Unggas dan Usaha Pemotongan Ayam. Jakarta: Menteri Pertanian.

Thoha. 1982. Strategi Menuju Kehidupan Berkelanjutan. Jakarta: Gramedia

Wardhana. 1994. Pencemaran Lingkungan. $\quad$ Yogyakarta: Penerbit Andi Offset.

Yuwono, A. dkk. 2007. Lingkungan Hidup (the living environment). Edisi II. Jakarta: Institut Pendidikan dan Pengembangan Lingkungan (IPPL). 